\title{
Doctor-Patient Communication: Principles and Practices
}

\author{
Suzanne M. Kurtz
}

\begin{abstract}
Background: In a formal needs assessment, conducted prior to the Canadian Headache Society's recent national continuing education workshop, participants expressed particular enthusiasm for enhancing their own communication skills or their teaching of those skills. Objectives: Responding to both interests, this paper offers a practical conceptual framework for thinking systematically about how to improve physician-patient communication to a professional level of competence. Methods: The three-part, evidence-based framework first defines communication in medicine in terms of five underlying assumptions about communication and the learning of communication skills. It then discusses three categories of communication skills (content, process, and perceptual skills) and six goals that physicians and patients work to achieve through their communication with each other. The second part of the framework explores "first principles" of effective communication and includes a brief look at the historical context that has significantly influenced our thinking about, and practice of communication in health care. Part three of the framework describes one approach for delineating and organizing the specific skills that research supports for communicating effectively with patients - the Calgary Cambridge Guide. Results: It is clear from the literature that better physician communication skills improve patient satisfaction and clinical outcomes and that good communication skills can be taught and learned. Conclusions: It is important that physicians learn the principles of good physician-patient communication and apply them in clinical practice. Medical education programs at all levels should include teaching of physician-patient communication.
\end{abstract}

RÉSUMÉ: La communication médecin-patient: principes et pratiques. Introduction: Lors d'une évaluation formelle des besoins, effectuée avant l'atelier d'éducation médicale continue de la Canadian Headache Society tenu récemment, les participants ont manifesté le désir d'augmenter leurs aptitudes à communiquer ou leur expertise dans l'enseignement de ces aptitudes. Objectifs: En réponse à ces deux besoins, cet article offre un encadrement conceptuel pratique pour concevoir systématiquement comment améliorer la communication médecin-patient jusqu'à un niveau de compétence professionnel. Méthodes: Le modèle en trois parties, basé sur des données probantes, définit la communication en médecine en termes de cinq prémices sous-jacentes à la communication et à l'apprentissage des compétences en communication. Suit une discussion sur trois catégories d'aptitudes (contenu, processus et aptitudes de perception) et six buts que les médecins et les patients visent à atteindre dans leur communication entre eux. La deuxième partie du modèle explore les principes de base de la communication efficace et inclut un aperçu du contexte historique qui a influencé significativement notre pensée et notre pratique de la communication dans les soins de santé. La troisième partie du modèle décrit une approche pour définir et organiser les compétences spécifiques appuyées par la recherche sur la communication efficace avec les patients - les Calgary Cambridge Guides. Résultats: D'après la littérature, il est clair que de meilleures aptitudes à communiquer chez le médecin améliore la satisfaction du patient et les résultats cliniques et que de bonnes aptitudes à communiquer peuvent être enseignées et apprises. Conclusions: Il est important que les médecins apprennent les principes d'une bonne communication médecin-patient et les appliquent en pratique clinique. Les programmes d'éducation médicale à tous les niveaux devraient inclure l'enseignement de la communication médecin-patient.

Can. J. Neurol. Sci. 2002; 29: Suppl. 2 - S23-S29

When I first began working with communication in medicine back in the 1970s, clinical competence included only three items: medical technical knowledge, physical examination, and medical problem solving. Communication was missing from the list. In fact, when some of us suggested in those early years that formal communication education and evaluation become part of the medical school curriculum, the response all too often was some version or another of: "AARRGGHH!"

A lot has changed since then. Today it is rare to find anyone who would not agree that communication is a basic clinical skill and support for formal communication skills training at all levels of medical education has mushroomed. Professional organisations and accrediting agencies are part of the strength behind this shift. Patient advocacy groups, researchers, medical educators, funding agencies, and health care providers themselves have also put their weight behind the movement to improve communication education and practice in health care. Indeed, this has become a cross-cultural phenomenon, not only in Canada which has been one of the leaders - but also in Australia, Britain,

From the Faculties of Medicine and Education, University of Calgary, Calgary, Alberta Reprint requests to: S.M. Kurtz, Education Tower 1102, 2500 University Drive NW, Calgary, Alberta T2N 1N4 Canada. 
Israel, the Netherlands, the Scandinavian countries, South Africa, Spain, the United States, and elsewhere.

Two primary factors have been responsible for this major shift in attitude and practice. The first factor was the exponential growth of the evidence base regarding communication in medicine and the advocacy that has resulted from that research. While substantive evidence was already available as much as 20 or 30 years ago, most of the work has been done in the past decade. The second development was the advent of videotape, which allowed us to improve both our research and our teaching methods in this area.

As the needs assessment for the symposium on which this supplement is based showed, these changes in attitude and practice have had an impact on Canadian neurologists. Many of those attending this symposium expressed enthusiasm for enhancing their own communication skills or their teaching of those skills. Here I offer a structure - a sort of conceptual framework - for thinking about how to improve physicianpatient communication more systematically and intentionally.

The conceptual framework has three parts. The first focuses on defining the domain in terms of underlying assumptions, types of communication skills and goals that we can achieve by enhancing communication skills in medicine. The second part of the framework explores what I call "first principles" of effective communication. The third part looks at one approach for delineating and organizing specific evidence-based skills for communicating with patients, namely the Calgary Cambridge Guide. For a more extensive discussion of the framework including the specific skills in the Guides, the evidence upon which they are based, and the proven methods for teaching communication in medicine - I refer you to two companion books that I co-authored with Drs J. Silverman and J. Draper. ${ }^{1,2}$

\section{DefinING THE DomaIn}

\section{Underlying assumptions}

Let's start with underlying assumptions. I have already established the first of these: communication is a basic clinical skill. The second assumption may be more contentious: communication is a series of learned skills or, as some would have it, a set of procedures for improving outcomes of care. Notice my use of the plural. To become more effective you have to focus on specific and numerous skills, not just some vague notion of improving communication in general. Learning to communicate effectively is a little like learning to play professional tennis. To become masterful you have to focus on various skills and strategies, not just the overall game and, like athletic skills honed to a professional level of competence, physician-patient communication skills will atrophy if you stop paying attention to them.

A corollary to the second assumption is also important: Communication is a learned skill rather than a personality trait. I am not saying that personality is altogether unconnected. Attitude and the desire to learn do influence learning; personality may influence both these factors. However, when it comes to communication, I contend that anyone who wants to learn can. In my experience, this pertains to everyone from enthusiastic beginning students to physicians whose communication with patients is resulting in formal complaints. As long as the communication problems are not the result of underlying psychiatric problems, even learners who are initially negative or defensive can, and do, learn to communicate more effectively with appropriate assistance once they can be moved to a position where they want to do so (and moving them to that position is not all that difficult).

Those who still doubt that communication can be taught may want to take a look at a recent review done by Aspergren ${ }^{3}$ for the Association for Medical Education in Europe. The review identified and quality graded 180 studies on teaching and learning communication skills in medicine. Eighty-one of these studies met the review's high or medium quality criteria, including 31 randomised trial studies, 38 open effect studies, and 12 descriptive studies. The review concludes that there is overwhelming support for the fact that communication can be taught and learned (in fact only one study found no change in skill, likely due to the brevity of the training period) and not just by students but by physicians at all levels of medical training and practice. The review also showed that specialists were as likely to benefit from learning communication skills as primary care doctors, a useful point since communication competence is equally important to both groups.

A third assumption is worth considering here: experience alone can be a poor teacher. While it is an excellent reinforcer of habit, it tends not to discern very carefully between good habits and bad. Peter Maguire's ${ }^{4}$ longitudinal study assessed how physicians'communication skills changed over their careers. He found that, without explicit intervention, most of the skills physicians acquired tended to be fixed in place by the end of residency. That is somewhat alarming to me, when I consider that most residents are learning communication skills at a time when these learners are exhausted, short on time, and in their own perception pushed to the limit and under everybody's thumbs. These are conditions counterproductive to the optimal learning of communication skills.

That students and residents are often trying to learn communication from either their personal experience or their observation of what their teachers model is troublesome for another reason, as well. Mentors and other clinical teachers generally do not distinguish between engaging in patient care and teaching medical problem solving at the bedside. Although learners perceive that they are watching their mentors model patient care in the "real" world, they are instead often seeing problem solving and the thinking that leads to diagnosis. Learners may observe snippets of patient care, but rarely do they get to observe - much less discuss - the gamut of communication skills involved in setting up relationships with patients for the first time, taking their complete or focused histories, doing explanation and planning, working with patients over time, etc. Unfortunately students begin to perceive that effective communication is simply problem solving. That's not to say that real care and exemplary communication don't happen. It's just that learners most often are not there to see it. By the same token mentors rarely observe complete learner-patient interviews. Consequently learners are rarely able to get detailed feedback on their own communication with patients. To return to the tennis metaphor, it would be like your tennis coach telling you that all you have to do to become a professional tennis player is watch a lot of tennis and then just go out and play a lot of games. 
Another problem with relying on experience alone is that we often don't perceive our own communication very accurately. Video and audiotape have made a major difference here. For example, in a study done some years ago researchers asked how much time physicians thought they were spending on patient education in a twenty minute interview. Physicians perceived themselves to be spending nine or ten minutes when in actual fact they were spending less than two minutes. ${ }^{5}$

A final set of assumptions has to do with what it takes to learn communication skills so as to change behaviour. First, knowledge by itself does not translate directly into performance. I can read a lot of books about tennis and improve my skills very little. To be able to understand is not the same as to be able to do. If you really want to enhance skills, five elements are necessary: ${ }^{1}$ - Systematic delineation and definition of skills to be learned.

- Observation of learners performing the skills (live or on videotape).

- Well-intentioned, detailed, descriptive feedback (preferably with videotape).

- Practice and rehearsal of skills.

- Repetition (i.e., a helical, reiterative model rather than a linear, once and done model).

Second, communication skills teaching or learning is different. Whether learners are students or physicians of many years' experience, communication is a skill set that people are already invested in. Compared to other learning in medicine, communication is more related to self-concept and self-esteem people perceive that how they communicate is part of who they are. Learners simply are not invested to the same degree in how they palpate a liver. Furthermore, with communication none of us starts from scratch, so learning something completely new is not a motivating factor here. In fact, communication is something learners have been doing for years and they think that what they are doing works, which is why they think they do it even though in many cases they have not examined very carefully just exactly what it is that they do.

Complexity confounds the issue further. Communication in medicine is not a simple matter. There is no achievement ceiling - you can never "arrive" and then just forget about maintaining mastered skills or learning even better ones. There are no quick fixes for improving patient-physician communication. Believe me, in the twenty-five years I have been doing this work I have tried to find one but, after looking at all kinds of alternatives and examining the literature repeatedly, none has appeared. Communicating at a professional level of competence involves a complex and interrelated set of skills. Learning, maintaining, and enhancing them is a life-long task.

The complexity issue will come up again when I discuss delineating and organizing specific evidence-based communication skills in the third part of my framework. Here, however, I would like to address another related concern that is uppermost in the minds of many physicians. Perhaps the largest perceptual problem we have in comprehensive communication training is concern as to whether this can all be done in the time allotted for medical interviews. Unquestionably time is a factor. (See Stewart et $\mathrm{al}^{6}$ for a brief literature review on the time factor.) Keep in mind, however, that the skills in the Guide complement or overlay what you are already doing medically and, in fact, they do not take much more time once they are mastered. On the other hand, we know that engaging in relationship or patientcentred care does take more time while you are in the process of mastering the skills. Consider a sports metaphor again. When I was learning to ski I can tell you that it took me 45 minutes to get down a hill that I can now easily ski in three minutes. The hill has not changed. My skill level has.

A relevant study compared physicians who engaged in patient-centred practice (which is very similar to relationshipcentred care) with those who did not engage in such practice. ${ }^{6}$ The latter took 7.8 minutes on average per consultation. Physicians who had mastered the patient-centred skills took 8.5 minutes - less than one minute longer. However, while they were learning the skills, physicians took nearly 11 minutes. If we really want to improve communication in medicine, we have to figure out how to set up the system so that clinicians - be they students or practising physicians - have time in their interactions with patients to learn, master, and maintain these new skills. Instead I fear that the health care "system" in its push for greater efficiency has us dangerously close to the edge when it comes to time. At some point, consultations really can become too short to do the job well from a communication or a medical perspective. True efficiency has to take accuracy, quality, and outcomes into account, not just time. (For a more detailed look at the issue of time see Stewart, Brown, et $\left.\mathrm{al}^{7}\right)$.

\section{Categories of Communication Skills}

To avoid confusion about what we are teaching in communication skills programs, we have found it useful to distinguish between three types of communication skills: ${ }^{1}$

- Content skills - what doctors say, e.g., the substance of the questions you ask and the answers you receive, the information you give, the differential diagnosis list, the medical knowledge base you work from

- Process skills - how doctors say it, e.g., how you ask questions, how well you listen, how you set up explanation and planning with the patient, how you structure your interaction and make that structure visible to the patient through signposting or transitions, how you build relationships with patients

- Perceptual skills - what you are thinking and feeling, e.g., awareness of your own decision making and other thought processes, awareness of and response to your own attitudes and emotions during an interview, whether you like or dislike the patient, your biases and prejudices, noise or discomfort that distracts you from attending to the patient

Content and process skills are more interpersonal in nature, while perceptual skills are more intra-personal. The three types of skills are inextricably linked - each influences the other. Until recently, communication process skills were given the least attention in medical education. Currently process skills tend to be the primary focus of communication skills programs while content and perceptual skills receive significant secondary emphasis.

\section{Goals of Communication Teaching and Learning}

A final piece in defining the domain has to do with the goals and outcomes we are working toward through communication training programs. What are we trying to accomplish by enhancing communication skills in medicine? The following is the evidence-based list of outcomes or goals around which I 
build my own training programs, regardless of whether I am working with medical students, residents, or practising clinicians:

- Promoting collaboration and partnership - promoting relationship-centred care

- Increasing:

- Accuracy

- Efficiency

- Supportiveness

- Enhancing patient and physician satisfaction

- Improving health outcomes.

Other articles in this supplement also discuss promoting partnership and relationship-centred care and they have provided a number of reasons for doing so, many of which are evidencebased. Although other approaches such as doctor-centred care or consumerism have their place, it is increasingly clear that relationship-centred care is most useful for accomplishing the rest of the listed outcomes. (Those who know the work of McWhinney and Stewart ${ }^{8}$ may use the term 'patient-centred care'instead.)

It is worth emphasising that enhancing physician-patient communication skills improves physician as well as patient satisfaction. Since physicians conduct some 200,000 interviews during their careers, it is worth paying attention to what might make those interactions more satisfying. Notice, too, that when we are talking about enhancing communication skills we are not just interested in psychosocial aspects of care. Numerous studies show that improving communication in specific ways also improves physiological outcomes. Readers may be familiar with the research that has been done around hypertension and pain control, and may be familiar with a study done by the Headache Study Group of the University of Western Ontario. ${ }^{9}$ This one year prospective study showed that the best predictor of resolution of headache problems after presenting at family physicians turned out to be not diagnosis, not intervention, not referral, not prescriptions. The best predictor for resolution of headache problems turned out to be the patient's perception that they had had an opportunity to tell their story and discuss their concerns about the headache fully with their physician during the first visit. This study ups the anti - it raises communication to a procedural level where we can begin to talk about communication as a treatment option that anyone can use.

Couple this information with another study done in the mid' 80 s that has become a classic. Beckman and Frankel ${ }^{10}$ found that, on average, physicians interrupted their patients 18 seconds into the interview. That study was recently redone. ${ }^{11}$ We have improved - now we are interrupting at 23 seconds and, as much as we think we are going to return to let the patient finish their story, it happened in only about $8 \%$ of the interviews in this study. That's doubly alarming once we consider that telling their full story turns out to be an important procedure for patients in headache care.

With respect to the relationship between communication and outcomes of care it is also worth looking at an extensive review of the literature on compliance done by Coambs et $\mathrm{al}^{12}$ in Canada. This review concluded that high levels of compliance were associated only with models that took into account patient attitudes, beliefs and intentions or those models in which the doctor-patient relationship was a negotiated process characterised by greater agreement and increased understanding.

This set of goals gives you some idea of where we are heading with what we are going to be recommending for improving communication in health care. One additional overall goal is also important to consider here:

- Improving communication in practice to a professional level of competence.

Personally I am interested in communication training in medicine only if we are aiming toward improving communication in actual practice - and not just with a lick and a promise but to a professional level of competence. Like Miller, ${ }^{13}$ I am interested not just in knowledge (do you know it?) or competence (can you do it?), but in performance (do you [choose to] do it?).

We have been successful at improving medical students' skills - they perform beautifully on examinations and within courses - but we have been stymied in this final objective. We need to make communication 'pros'out of everybody who goes into clinical medicine. It is a doable task. However, it is possible only if we carry communication training through to clinical clerks, residents, and practising physicians in such a way that the modelling can continue to improve and that physicians including those who teach clinical medicine - can speak more intentionally about what they do in this domain. With this in mind, it was refreshing to see a large group of practising physicians - many of whom had been in practice for years - in attendance at our communication symposium for the purpose of really looking at communication skills enhancement.

\section{First Principles of Communication}

Enough on assumptions, types of skills, and outcomes. I would like to move on to what I call 'first principles' of effective communication, beginning with a brief but important look at the historical context. ${ }^{14}$ With his customary wit, Alton Barbour suggests that attempts to improve communication across the centuries can be reduced to two basic perspectives:

- the shot-put approach

- the Frisbee approach.

Not surprisingly, the shot-put approach originated in classical Greek times. This approach defines communication simply as the well-conceived, well-delivered message. Part of our problem with communication may be that from those classical beginnings right up through the early 20th Century, formal communication training in the professions has focused almost entirely on the shot-put approach. Effective communication was content, delivery, and persuasion - no one imagined it could be otherwise. A mid-20th century communication model developed by a telephone company reflects this "shot-put" approach: someone put together a good message and transmitted it, someone picked it up, and that was the end of the communication picture. The notion of feedback was nowhere to be seen.

In the 1940s, the focus began to shift toward interpersonal communication - alias, the Frisbee approach. This new perspective finally caught on in the 1960s. As Barbour suggests, two concepts are central to this interpersonal approach. Both are significant to communication in medicine. The first concept is confirmation. I like R.D. Laing's definition: to recognise, acknowledge, and endorse another person. For those of you with 
a more philosophical or theological bent, confirmation in Martin Buber's language means "I-Thou" rather than "I-It" relationships.

The second concept central to this interactive Frisbee approach is mutually understood common ground. This common ground that both people in an interaction are aware of is a necessary foundation for trust and accuracy. Decades ago Baker ${ }^{15}$ called this idea "reciprocal identification" and pointed out that people reach a conscious, mutual understanding of the common ground they share primarily by talking with each other about it. In fact, Baker went so far as to contend that the reason we communicate is so that we can be together comfortably in silence. Baker's model provides an excellent remedy for those moments in an interview when you sense discomfort or defensiveness or tension between you and your patient - simply (re)establish some sort of mutually understood common ground.

Relating this more closely to communication in medicine, Starfield ${ }^{16}$ found that resolution of patient problems requiring follow-up improved if doctor and patient had come to agreement regarding the problem(s). However, Starfield's study found such agreement in only about $50 \%$ of the cases analysed. Stewart and her colleagues ${ }^{17}$ did an extension of this work and found that in primary care settings about $50 \%$ of the problems and concerns patients came in with were in fact not uncovered at all, much less agreed upon. If you add to these findings the research I mentioned earlier about how quickly physicians interrupt patients ${ }^{10,11}$ and the importance of headache patients telling their full story, ${ }^{9}$ you begin to appreciate the significance of mutually understood common ground in physician-patient communication. Additional insight is gained from yet another study in which Stewart and colleagues ${ }^{18}$ concluded that finding common ground with patients in the decision making process resulted in fewer referrals, fewer return visits, and fewer investigations.

If confirmation and mutually understood common ground are important to effective communication then our time-honoured, one-dimensional focus on the well-conceived, well-delivered message falls short. In the interpersonal or Frisbee perspective the message is still important, of course, but the emphasis shifts to interaction, feedback, collaboration - in a word, relationship. In a similar way, approaches to communication in health care have shifted from a content focus to doctor-centred communication, consumerism, and most recently, relationshipcentred care.

Given this historical context, I have found it useful to define "effective communication" in terms of five principles. ${ }^{1,19,20}$ For those who are teaching, these same five principles characterise effective teaching. Effective communication (or teaching):

- Ensures interaction not just transmission - just giving information (whether it comes from the physician or the patient) or telling someone what to do without feedback and other opportunities for the give and take of questions and responses, clarification, etc. hinders accuracy, efficiency, and relationship building. Establishing mutually understood common ground and confirmation require interaction.

- Reduces unnecessary uncertainty - uncertainty distracts attention and interferes with accuracy, efficiency, and relationship. We can, for example, reduce uncertainty about the role a given physician will play in the patient's care, the illness the patient comes in with, anticipated outcomes of care, the patient's expectations for the visit, the physician's expectations, how the health care team works, how specialist and primary care doctor will relate, etc.

- Requires planning, thinking in terms of outcomes effectiveness can only be determined in the context of the outcomes you and/or the patient are working toward. If you are angry and want to vent that anger then you communicate in one way, but if you want to get at the misunderstanding that caused the anger then you must do something entirely different.

- Demonstrates dynamism - this principle has multiple meanings. First, dynamism means engaging with the patient, being there in the moment. Second it means flexibility and points toward the need for physicians to develop a repertoire of skills which allow different approaches with different patients or with the same patient in different circumstances. To interact effectively you have to play off the other person and we're back to the Frisbee approach.

- Follows a helical rather than a linear model - once and done is not enough; if you want accurate understanding you have to go over information again and perhaps again, in helical fashion, each time moving up the spiral to a little different level of understanding. Repetition, reiteration, feedback are essential elements of effective communication. Returning to the parallel between effective communication and effective teaching, the helix also serves as an excellent learning/teaching model. Developing communication skills and maintaining competence requires reiteration over time as skills are deepened and applied in different contexts.

\section{Evidence-Based Skills for Communicating with Patients}

So far, I have laid out a conceptual framework for systematically improving communication in medicine that includes assumptions, definitions, goals and first principles (Table 1). One significant part of that framework remains if you want to move from theory to practice. Return for a moment to the final set of assumptions about the elements that are necessary if you really want to deepen your own communication skills or assist others to enhance theirs. At the top of that list of elements was the delineation and definition of the skills themselves. All the other necessary elements - observation, feedback, rehearsal, and repetition - are dependent on that first nitty gritty component.

So just what are the skills that make a difference in communication between doctors and patients? My answer with respect to communication process skills is the Calgary Cambridge Observation Guide (CC Guide). ${ }^{1,2,21}$ (Incidentally this same set of skills, with very few exceptions, works as a guide to improving communication in teaching - simply substitute student and teacher for patient and doctor throughout the document.) The CC Guide has gone through many iterations which drew on the work of several individuals: Rob SansonFisher in Australia, Peter Maguire in England, Don Cassata and Paula Stillman in the United States, Cathy Heaton in Canada, and most recently, Jonathan Silverman in England. An American geneticist, Vic Riccardi, and I published an earlier version; ${ }^{22}$ many students and the community physicians and faculty who teach them communication have added their feedback. The CC 
Table 1: Defining the domain

\section{Underlying assumptions}

Communication is a basic clinical skill

Communication in medicine is a series of learned skills

- not a personality trait

- anyone can learn who wants to

Experience can be a poor teacher

Knowledge of skills does not translate directly into performance

Essentials needed to learn skills, change behaviour:

- systematic delineation and definition of skills

- observation of learners with patients

- well-intentioned, detailed, descriptive feedback

- practice and rehearsal of skills

- planned reiteration and deepening of skills

Categories of skills

Content skills - what doctors do

Process skills - how they do it

Perceptual skills - what they are thinking and feeling

Goals of medical communication

Promoting collaboration and partnership

Ensuring increased

- Accuracy

- Efficiency

- Supportiveness

Enhancing patient and physician satisfaction

Improving health outcomes

Approaches to communication

Shot-put approach: the well-conceived, well-delivered message

Frisbee approach: interaction, feedback, relationship, confirmation, common ground

Principles that characterise effective communication

Ensures an interaction rather than a direct transmission process

Reduces unnecessary uncertainty

Requires planning and thinking in terms of outcomes

Demonstrates dynamism

Follows the helical model

Guide is evidence-based. ${ }^{2}$ Its approximately 70 items provide a useable summary of the research literature on what skills make a difference in doctor-patient communication. As such, the $\mathrm{CC}$ Guide will always be a work in progress that will continue to evolve to reflect developments in research.

It's interesting that when they first see the $\mathrm{CC}$ Guide practising physicians tend to groan at the length (particularly if it is offered without first giving them a chance to [re]create the skills list for themselves). Students, on the other hand, cheer and tell us how delighted they are to know, for once, exactly what they have to learn. In any case, we admit without apology that the list of skills is long - effective communication in medicine is complex and the research on it extensive. To make the 70 -odd skills more memorable and accessible, we organise them around a number of logical headings and subheadings (Table 2). This structure reflects the tasks that are undertaken in any medical interview: initiating the interview, giving information, relationship building, explanation and planning, and closing the interview. These tasks, with the exception of relationship building (and structuring the interview), generally follow in sequential order. Relationship building occurs throughout any given consultation; indeed virtually everything on the CC Guide contributes to relationship. We include it as a separate category simply so that we have somewhere to put those relationship building skills which don't quite fit under any of the other headings.

Does all this mean that the 70 skills on the Guide are needed in every doctor-patient interaction? The answer, of course, is no. Which communication skills are needed depends on the situation at hand and the specific (and sometimes different) outcomes the patient and the physician are trying to achieve through their interaction. One last sports analogy: to play good basketball you need a full repertoire of well-developed skills and you do have to stay focused. But that doesn't always require the intensity of a full court press.

The CC Guide reflects the state of the art - or the state of the evidence, if you prefer - for communication training in medicine. I am aware of more than a dozen countries where it is currently in use, so it has wide cross-cultural applicability. It has been used at all levels of medical education, from first year medical students to practising physicians and in virtually all the specialties. An overall framework for systematic skill development, the Guide serves as a basis for comprehensive rather than hit-and-miss feedback. It offers guidance but with considerable latitude for individual style and personality.

The basis, then, for including each skill on the Guide includes the research evidence, theoretical concepts, and extensive experience, as well as the principles of effective communication

Table 2: The Framework of the Calgary Cambridge Guide

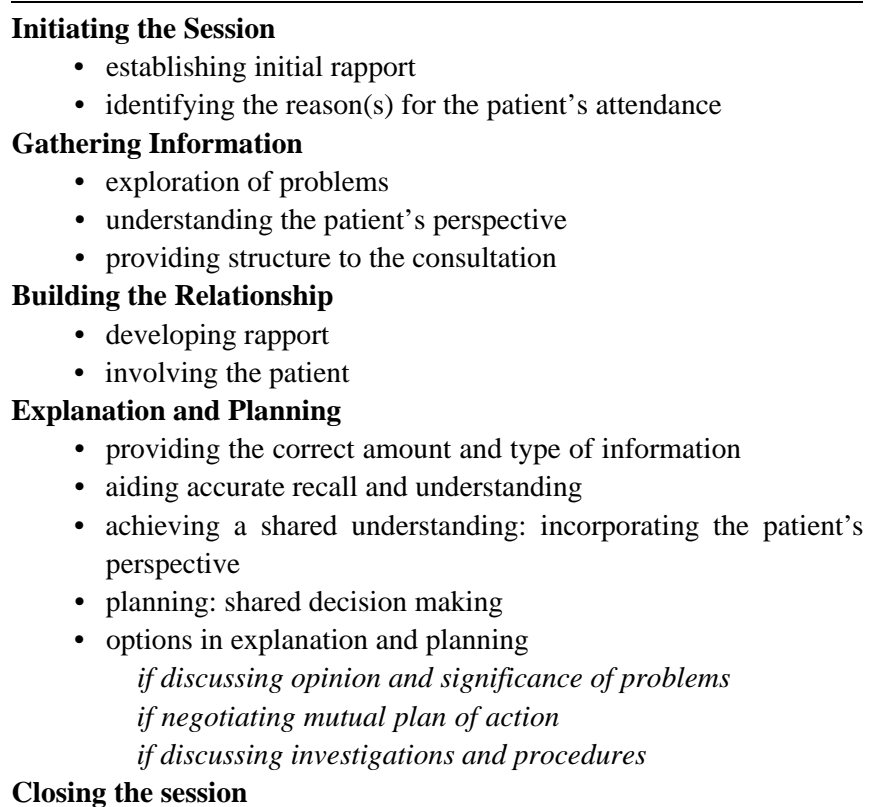


and the communication goals of accuracy, efficiency, and supportiveness. Our book, Skills for Communicating with Patients, ${ }^{2}$ describes the specific research and theoretical evidence behind each skill. With separate chapters for each major task, the book also offers detailed explanations and several examples of how you might implement each skill in practice. Our companion book, Teaching and Learning Communication Skills in Medicine, ${ }^{1}$ is appropriate for those of you wanting to teach or learn these skills. Again emphasising the evidence base, it describes best teaching practice, how and why we developed the Guide, and how to build curricula around it. It also describes various ways to use the Guide and other methods for working with medical students, residents, and practising clinicians.

If we work to enhance communication skills in medicine, the prize on offer is substantial. That prize includes:

- More effective consultations with respect to accuracy and common ground, efficiency, supportiveness, collaboration, and reduced conflicts and complaints.

- Improved outcomes in terms of patient and physician satisfaction, understanding and recall, adherence to treatment plans, symptom relief, and physiological outcomes.

Over the years people have said to me too often: "Yes but if you had to decide between a doctor with effective communication skills and one with medical competence, which would you choose?" Given all that we know, my resolute response has become: "We shouldn't have to choose anymore."

\section{REFERENCES}

1. Kurtz S, Silverman J, Draper J. Teaching and Learning Communication Skills in Medicine. Oxford: Radcliffe Medical Press, 1998.

2. Silverman J, Kurtz S, Draper J. Skills for Communicating with Patients. Oxford: Radcliffe Medical Press, 1998.

3. Aspergren K. Teaching and learning communication skills in medicine: a review with quality grading of articles. Med Teach $1999 ; 21(6)$.

4. Maguire P, Fairbairn S, Fletcher C. Consultation skills of young doctor: II - Most young doctors are bad at giving information. BMJ 1986;292:1576-8.

5. Waitzkin H. Information giving in medical care. J Health Soc Behav 1985;26:81-101.

6. Stewart MA. Comparison of Two methods of analysing doctor- patient communication. Paper presented at the North American Primary Care Research Group, Seattle. 1985.

7. Stewart M, Brown JB, Boon H, et al. Evidence on patient-doctor communication. Cancer Prev Control 1999; 3(1): 25-30.

8. Stewart M, Belle Brown J, Weston WW, et al. Patient Centred Medicine: Transforming the Clinical Method. Thousand Oaks, California: Sage, 1995.

9. The Headache Study Group of the University of Western Ontario. Predictors of outcome in headache patients presenting to family physicians - a one year prospective study. Headache J 1986;26: 285-294.

10. Beckman HB, Frankel RM. The effect of physician behaviour on the collection of data. Ann Int Med 1984;101:692-696.

11. Marvel MK, Epstein RM, Flowers K, Beckman HB. Soliciting the patient's agenda: have we improved? JAMA 1999;281(3), 283287.

12. Coambs RB, Jensen P, Hoa Her M, et al. Review of the Scientific Literature on the Prevalence, Consequences, and Health Costs of Noncompliance \& Inappropriate Use of Prescription Medication in Canada. Ottawa: Pharmaceutical Manufacturers Association of Canada (University of Toronto Press), 1995.

13. Miller GE. Commentary on clinical skills assessment: a specific review. Philadelphia: National Board of Medical Examiners 75th Anniversary 1990:48-51.

14. Barbour A. Making contact or making sense: functional and dysfunctional ways of relating. Paper presented for Humanities Institute Lecture 1999-2000 Series, University of Denver, 2000.

15. Baker SJ. The theory of silences. J Gen Psychology 1955; 53:145.

16. Starfield B, Wray C, Hess K, et al. The influence of patientpractitioner agreement on outcome of care. AJPH. 1981;71:127131.

17. Stewart MA, McWhinney I, Buck CW. The doctor-patient relationship and its effect upon outcome. J R Coll Gen Pract 1979;29:77-82.

18. Stewart M, Belle Brown J, Donner A, et al. The impact of patientcentred care on patient outcomes in family practice (Research Report: Thames Valley Family Practice Research Unit, Ontario), 1997.

19. Dance FEX, Larson CE. Speech communication: concepts and behaviour. New York: Holt, Rinehart and Winson, 1972.

20. Dance FEX. Toward a theory of human communication. In: Dance FEX, (Ed). Human Communication Theory: Original Essays. New York: Holt, Rhinehart, Winston, 1967.

21. Kurtz SM, Silverman JD. The Calgary-Cambridge Observation Guides: an aid to defining the curriculum and organising the teaching in communication training programmes. Med Ed 1996;30:83-89.

22. Riccardi VM, Kurtz SM. Communication and counseling in health care. Springfield, Illinois: Charles C Thomas, 1983. 